\title{
GESTÃO DE RISCO NAS ATIVIDADES DE INVESTIMENTO DOS REGIMES PRÓPRIOS DE PREVIDÊNCIA SOCIAL (RPPS) DOS MUNICÍPIOS DO ESTADO DO RIO GRANDE DO SUL
}

\author{
Nadia Mar Bogoni \\ nbogoni@upf.br \\ Universidade de Passo Fundo - RS / Brasil \\ Francisco Carlos Fernandes \\ franciscofernandes@furb.br \\ Universidade Regional de Blumenau - SC / Brasil
}

Recebido em 09/08/2008

Aprovado em 20/12/2010

Disponibilizado em 01/04/2011

Avaliado pelo sistema double blind review

Revista Eletrônica de Administração

Editor: Luís Felipe Nascimento

ISSN 1413-2311 (versão on-line)

Editada pela Escola de Administração da Universidade Federal do Rio Grande do Sul.

Periodicidade: Quadrimestral

Sistema requerido: Adobe Acrobat Reader.

\section{INTRODUÇÃO}

O sistema previdenciário constitui-se em um dos principais problemas estruturais das contas públicas no Brasil. Segundo Afonso e Fernandes (2005), aspectos demográficos, mudanças no mercado de trabalho e os efeitos da Constituição de 1988 são alguns fatores que explicam o desequilíbrio financeiro e atuarial do sistema previdenciário público brasileiro. A busca pela redução dos gastos previdenciários é uma das principais características da reforma previdenciária iniciada no final da década de 1990. Esta reforma teve como marco principal a aprovação da Emenda Constitucional (EC) nº 20 em 16 de dezembro de 1998.

A referida Emenda Constitucional (EC) $n^{\circ} 20$ criou o sistema de previdência para os servidores públicos da União, Estados, Distrito Federal e Municípios, definido como Regime Próprio de Previdência Social (RPPS). Tais entidades caracterizam-se como fundos de pensão, os quais passam, inicialmente, por uma fase de acumulação de recursos, na qual se coleta dinheiro dos trabalhadores ativos e dos órgãos públicos empregadores, e, 
GESTÃO DE RISCO NAS ATIVIDADES DE INVESTIMENTO DOS REGIMES118

PRÓPRIOS DE PREVIDÊNCIA SOCIAL (RPPS) DOS MUNICÍPIOS DO ESTADO

DO RIO GRANDE DO SUL

posteriormente, por uma fase de pagamento de benefícios, quando o beneficiário adquire as condições para habilitar-se à percepção de algum dos benefícios instituídos pelo RPPS.

Durante o período de acumulação, que ocorre entre o instante em que o participante adere ao regime e o início da fase de pagamento de benefícios, o RPPS vai investir os recursos e obter um retorno para seus investimentos.

Esse retorno será o diferencial que permitirá pagar os benefícios e, caso o retorno dos investimentos não seja adequado, a solvência da entidade poderá ser afetada e sua continuidade estará ameaçada. É necessário, portanto, que cada RPPS obtenha e mantenha ao longo do tempo uma condição de equilíbrio atuarial, tornando-se fundamental que exista um determinado nível mínimo de resultados das aplicações financeiras realizadas com os fundos previdenciários.

As aplicações financeiras dos RPPS são regulamentadas por resoluções do Conselho Monetário Nacional (CMN), como, por exemplo, a Res. 3.506/07 ${ }^{1}$, que busca garantir que os recursos previdenciários sejam aplicados dentro de padrões mínimos de segurança e rentabilidade.

Citando-se alguns estudos internacionais sobre fundos de pensão, tem-se Bodie (1988), Garcia (2003), Helbronner (2005) e Yermo (2008), que contemplaram a importância da diversificação das carteiras, a busca por maiores rentabilidades, os riscos associados aos principais fundos de investimentos e a importância de acompanhamento pelos gestores e do estabelecimento de boas práticas de governança, visando garantir a obtenção da performance necessária ao equilíbrio atuarial dessas entidades, sua liquidez e solvência.

Com relação a estudos nacionais sobre fundos de pensão, tem-se Herranz (1995), Gulias Júnior (2005) e Ferreira (2006), entre outros. Herranz (1995) estabeleceu a necessidade de delimitar percentuais máximos de alocação dos investimentos, como padrão de segurança, em virtude do risco moral dos gestores dos planos de benefício. Gulias Júnior (2005) verificou se o nível de exposição ao risco de mercado imposto aos ativos administrados pelos fundos de pensão é compatível com a cobertura do passivo atuarial dos seus planos de benefícios. $\mathrm{O}$ trabalho foi conduzido por meio de um estudo de caso na Fundação dos Economiários Federais (FUNCEF) e utilizou como instrumentos para a realização dos testes empíricos o Value-at-Risk (VaR) e a formação de fronteiras eficientes, conforme a Teoria das Carteiras, desenvolvida por Markowitz. Ferreira (2006) analisou a política de investimentos do Fundo

\footnotetext{
1 A alterada pela Resolução 3.790/09. O estudo reporta-se a política de investimentos praticada pela Resolução 3.506/07, tendo em vista o artigo ter sido enviado para publicação no ano de 2008 e aceito em 2010.
}

REAd - Edição 68, Volume 17, No 1, jan/abr 2011 - p. 117-148 
de Previdência do Estado de Minas Gerais (FUNPEMG), que se constitui em um RPPS e que segue as regulamentações estabelecidas na Resolução do CMN no 3.244/2004. O autor verificou o risco de perdas financeiras e de desempenhos diários inferiores à referida meta, a partir dos dados do FUNPEMG e por Simulações de Monte Carlo baseadas em investimentos que atendem aos critérios definidos na Resolução.

Os vários enfoques apresentados nos estudos citados envolvem a gestão de risco, o gerenciamento de ativos e passivos e a superação de metas atuariais, dentre outros aspectos que envolvem a gestão de investimentos em fundos de pensão. As abordagens citadas demonstram a relevância do gerenciamento de riscos como forma de se aperfeiçoarem os controles para que os níveis de retorno sejam compatíveis com o comportamento dos passivos atuariais e de se manter a solvência dos fundos de pensão.

A gestão de investimentos inclui a adequada estruturação dos riscos inerentes às operações financeiras, tanto que a essência da teoria de finanças já esclarece que não existe retorno obtido sem que algum nível de risco seja assumido. A crise econômica atual oferece uma clara demonstração de como é importante a consideração desses riscos e de como é grande a sua diversidade.

Assim sendo, é notória a importância que as entidades previdenciárias, aqui tratadas como RPPS, possuem no âmbito da sociedade, seja pelo alcance social de sua atividade no campo previdenciário ou pelo papel que exercem no ambiente econômico como investidores institucionais. A falta de mecanismos de controle de riscos torna essas entidades susceptíveis à baixa lucratividade, comprometendo a manutenção da liquidez, da solvência e do equilíbrio econômico e atuarial desses fundos.

Diante do exposto, tem-se como objetivo desta pesquisa avaliar os mecanismos de controle de riscos adotados pelos RPPS nas atividades de investimento como forma de garantir a proteção e o equilíbrio financeiro e atuarial. Em especial, este estudo busca: a) caracterizar a gestão praticada pelos RPPS no Rio Grande do Sul; b) identificar a política de investimentos praticada pelos gestores dos fundos do RPPS; c) analisar as práticas de gestão de investimentos que estão sendo adotadas pelos RPPS para aumentar as condições de segurança, rentabilidade e transparência; d) verificar quais sistemas de apoio à gestão de investimento são adotados pelos gestores dos RPPS; e) avaliar, por meio da análise de agrupamentos, o grau de distanciamento existente nas práticas de gestão de riscos executadas nos RPPS dos municípios do Rio Grande do Sul. 
GESTÃO DE RISCO NAS ATIVIDADES DE INVESTIMENTO DOS REGIMES120

PRÓPRIOS DE PREVIDÊNCIA SOCIAL (RPPS) DOS MUNICÍPIOS DO ESTADO

DO RIO GRANDE DO SUL

A contribuição deste estudo está pautada nas informações que serão produzidas em relação à gestão de riscos adotada pelos regimes próprios de previdência social, as quais poderão dar suporte aos órgãos gestores dos RPPS por ocasião da elaboração de novas Leis e Resoluções que norteiam e regulamentam o funcionamento destes fundos.

Ou seja, os resultados alcançados poderão subsidiar tanto os gestores dos fundos do RPPS na tomada de decisões com relação aos investimentos, quanto os órgãos reguladores em seu processo de elaboração de normas. Considera-se ainda que a criação dos RPPS foi um dos marcos da reforma previdenciária iniciada no final da década de 1990, cujo principal objetivo econômico fundamentou-se no saneamento de problemas estruturais das finanças públicas. Logo, a busca pela redução dos gastos previdenciários e, consequentemente, o equilíbrio financeiro e atuarial, é uma das principais missões dos RPPS. Além disso, a pesquisa justificase pela importância que do previdenciário, que é responsável pelo pagamento de aposentadorias e pensões a um grande número de servidores públicos. Só no Rio Grande do Sul (RS), essas entidades são responsáveis pelas aposentadorias de servidores de 303 municípios.

\section{REFERENCIAL TEÓRICO}

\subsection{Os Regimes Próprios de Previdência Social (RPPS)}

Um dos maiores desafios econômicos colocados diante dos administradores públicos é a questão previdenciária. De acordo com Tafner e Giambiagi (2007), ao fundar um sistema de seguro social sob controle, gestão e operação do Estado e estruturado com base em contribuições de trabalhadores e de seus patrões, o Estado moderno trouxe para si o risco implícito associado a esse sistema, ou seja, o risco de desequilíbrio entre o montante esperado de contribuições e o montante esperado de pagamentos (benefícios).

Considera-se esse mecanismo um dos principais responsáveis pelo grave desequilíbrio apresentado pelas contas públicas no Brasil. Na visão de Tafner e Giambiagi (2007) o sistema de previdência no Brasil tem sido um severo elemento de restrição fiscal, atingindo déficits da ordem de 5\% do PIB em 2006, marca que coloca o país no grupo dos maiores déficits previdenciários do mundo. Assim sendo, a necessidade de equacionamento do sistema de previdência do país é considerada pelos autores um dos pilares mestres para a organização das contas públicas que, consequentemente, irão promover o crescimento econômico e sustentado do Brasil.

REAd - Edição 68, Volume 17, No 1, jan/abr 2011 - p. 117-148 
A busca pela modernização da administração do regime de previdência instituído pela Emenda Constitucional 20/98 vem apresentando avanços regulatórios e de gestão, sempre com o intuito de promover a rentabilidade, liquidez, solvência, equilíbrio financeiro e atuarial e transparência dessas entidades e, ao mesmo tempo, garantir a aposentadoria de um grande número de servidores públicos participantes desses fundos.

Esse cenário requer o entendimento de mecanismos de controle e de gestão dos riscos inerentes aos RPPS, pois são instrumentos capazes de produzir informações relevantes aos gestores desses fundos e que auxiliam na tomada de decisões.

A fim de garantir equilíbrio financeiro e atuarial aos RPPS, a partir de setembro de 1999 o CMN/BACEN vem editando normas para a regulamentação destes fundos, destacando-se: Resolução CMN n 2.652/1999, Resolução CMN n 3.244/2004 e Resolução CMN no 3.506/2007. Todas estas Resoluções dispõem sobre as aplicações dos recursos dos RPPS instituídos pela União, Estados, Distrito Federal e Municípios.

A Resolução CMN nº 3.506/2007, objeto deste estudo, dispõe sobre a alocação dos recursos do RPPS, bem como sua política de investimentos; os segmentos de aplicação (renda fixa, variável e imóveis) e dos limites para cada segmento; a gestão dos fundos e as obrigações dos gestores deste fundos.

Este estudo pretende trazer informações e métricas relativas à política de investimentos que vem sendo praticada nos RPPS do Rio Grande do Sul, dentre as quais: limites de concentração de investimentos, limites de riscos (de mercado, crédito e liquidez), limites de créditos com cada intermediário financeiro, conseqüências das violações da política de investimentos, nível de transparência, métodos utilizados pelos Gestores dos RPPS para a avaliação de Riscos, entre outras. Ou seja, a partir deste estudo, pode-se evidenciar se os RPPS do Rio Grande do Sul cumprem os dispositivos impostos pela legislação vigente.

O Quadro 1, apresentado a seguir, mostra as exigências da Res. 3.506/2007 sobre a política de investimentos e as informações e métricas levantadas neste estudo correspondentes a cada uma delas.

REAd - Edição 68, Volume 17, No 1, jan/abr 2011 - p. 117-148 
GESTÃO DE RISCO NAS ATIVIDADES DE INVESTIMENTO DOS REGIMES122

PRÓPRIOS DE PREVIDÊNCIA SOCIAL (RPPS) DOS MUNICÍPIOS DO ESTADO

DO RIO GRANDE DO SUL

\begin{tabular}{|c|c|}
\hline Exigência da Res. 3.506/2007 & Métricas adotadas neste estudo \\
\hline $\begin{array}{l}\text { Contemplar o modelo de gestão a ser adotado e, se } \\
\text { for o caso, os critérios para a contratação de pessoas } \\
\text { jurídicas autorizadas ou credenciadas para o } \\
\text { exercício profissional de administração de carteiras } \\
\text { (Art. } 4^{\circ} \text {, Inciso I) }\end{array}$ & $\begin{array}{l}\text { - Forma de gestão quanto à aplicação dos fundos dos } \\
\text { RPPS; } \\
\text { - Consequências das violações da política de } \\
\text { investimentos por parte dos gestores; } \\
\text { - Necessidade de segregação de função entre os } \\
\text { responsáveis pelas operações de investimentos e os } \\
\text { responsáveis pelo processamento dos documentos; } \\
\text { - Responsabilidades sobre a escolha de alternativas } \\
\text { de investimentos. }\end{array}$ \\
\hline $\begin{array}{l}\text { Definir a estratégia de alocação dos recursos entre } \\
\text { os diversos segmentos de aplicação e as respectivas } \\
\text { carteiras de investimentos de acordo com o perfil de } \\
\text { suas obrigações, tendo em vista a necessidade de } \\
\text { busca e manutenção do equilíbrio financeiro e } \\
\text { atuarial e os limites de diversificação e } \\
\text { concentração previstos nas próprias Resoluções } \\
3.506 / 2007 \text { e 3.790/2009 (Art. } 4^{\circ} \text {, Inciso II) }\end{array}$ & $\begin{array}{l}\text { - Parâmetros a serem adotados para cálculo dos } \\
\text { níveis de exposição a riscos; } \\
\text { - Padrões e procedimentos para acompanhamento } \\
\text { dos ratings das instituições que recebem ou } \\
\text { administram recursos. }\end{array}$ \\
\hline $\begin{array}{l}\text { Definir os limites utilizados para investimentos em } \\
\text { títulos e valores mobiliários de emissão ou } \\
\text { coobrigação de uma mesma pessoa jurídica (Art. } 4^{\circ} \text {, } \\
\text { Inciso III) }\end{array}$ & $\begin{array}{l}\text { - Limites de concentração de investimentos em } \\
\text { determinados intermediários financeiros; } \\
\text { - Limites de risco de mercado; } \\
\text { - Limites de crédito a serem observados na condução } \\
\text { de negócios com cada intermediário financeiro; } \\
\text { - Se os limites de investimento estabelecidos nas } \\
\text { normas do RPPS permitem uma diversificação } \\
\text { adequada nos investimentos da entidade. }\end{array}$ \\
\hline $\begin{array}{l}\text { A política anual de investimentos dos recursos do } \\
\text { RPPS e suas revisões deverão ser aprovadas pelo } \\
\text { órgão superior de supervisão e deliberação, antes de } \\
\text { sua implementação (Art. } 5^{\circ} \text { ) }\end{array}$ & $\begin{array}{l}\text { - Participação de pessoas com conhecimentos } \\
\text { técnicos especializados em gestão de investimentos } \\
\text { na elaboração e revisão da política. }\end{array}$ \\
\hline $\begin{array}{l}\text { As informações contidas na política anual de } \\
\text { investimentos e suas revisões deverão ser } \\
\text { disponibilizadas pelos responsáveis pela gestão do } \\
\text { RPPS aos seus segurados e pensionistas, no prazo } \\
\text { de trinta dias, contados da data de sua aprovação } \\
\left(\text { Art. } 6^{\circ}\right) \text {. Esta exigência estava presente somente na } \\
\text { Res. 3.506/2007, tendo sido revogada na Res. } \\
\text { 3.790/2009 }\end{array}$ & $\begin{array}{l}\text { - Acessibilidade à política por parte dos participantes } \\
\text { do RPPS. }\end{array}$ \\
\hline
\end{tabular}

Quadro 1- Exigências da Resolução do CMN no 3.506/2007 em Relação à Política de Investimentos.

Note-se que, à exceção da exigência imposta no Art. $6^{\circ}$ da Res. 3.506/2007, todas as outras foram mantidas na Res. 3.790/2009.

\subsection{Riscos e Gestão de Riscos}

A mais famosa definição de risco, segundo Holton (2004), é aquela dada pelo economista Frank Knight (1921) que sugeriu a diferenciação entre a incerteza e o risco. A incerteza refere-se a situações em que uma decisão pode gerar muitos resultados, porém cada um deles apresenta possibilidades de ocorrência desconhecidas (a incerteza é imensurável). Por sua vez, o risco refere-se a situações relacionadas a todos os possíveis resultados, em que se conhece a possibilidade de cada resultado vir a ocorrer. Em outras palavras, risco é definido como uma incerteza mensurável e que pode ser determinada quantitativamente.

REAd - Edição 68, Volume 17, No 1, jan/abr 2011 - p. 117-148 
Securato (1993, p. 28) define risco como "a probabilidade de ocorrência do evento gerador da perda ou da incerteza". Dessa forma, a principal característica do risco é que a ele se pode associar um número que expresse a chance de ocorrência de um resultado a partir de uma decisão tomada. Para corroborar a relação existente entre risco e incerteza tem-se a expressão de Fabozzi (2000, p. 11), que afirma que "o risco é o grau de incerteza".

A gestão de riscos, por sua vez, pode ser compreendida como o processo pelo qual cada gerência ou gestor decide como os riscos, que representam ameaças aos objetivos sob sua gestão, serão tratados. Assim, o gerenciamento de riscos apresenta-se como maneira ou forma de investigar a lucratividade e a competitividade das entidades de diversos segmentos de mercado. Talvez o grande desafio da gestão de riscos seja, em tempos de constantes e profundas mudanças, buscar mecanismos que minimizem o impacto dos riscos advindos de tais mudanças.

\subsection{Gestão de Riscos nas Atividades de Investimentos dos RPPS}

Os diversos conceitos atribuídos ao risco e à incerteza têm em comum a probabilidade de que eventos incertos ocorram e que causem prejuízos às mais diversas entidades, em especial, às financeiras, dentre as quais se encontram os bancos, as seguradoras e os fundos de pensão.

As entidades financeiras abordadas neste estudo são os fundos de pensão do funcionalismo público. Fernandes (2000, p. 63) trata os fundos de pensão como um negócio financeiro pelos seguintes fatores: ênfase na administração de ativos financeiros, preponderância de um passivo eminentemente atuarial e sua qualidade de investidor institucional. Seguindo-se o raciocínio exposto por Fernandes (2000), poder-se-ia equiparar os RPPS aos fundos de pensão, e consequentemente, também às entidades financeiras, uma vez que os RPPS têm a finalidade de formar, progressivamente, reserva financeira necessária, visando garantir o pagamento de benefícios previdenciários para servidores públicos e seus dependentes legais.

As atividades dos RPPS, então, devem ser vistas como atividades fundamentalmente orientadas para a formação de resultados econômicos que serão obtidos por meio de investimentos capazes de garantir, no futuro, o pagamento da aposentadoria de seus participantes. Todos os eventos que possam afetar adversamente o equilíbrio dos ativos financeiros com os passivos atuariais dessas instituições representam riscos e, então, a gestão de riscos é de fundamental importância para essas atividades. 
GESTÃO DE RISCO NAS ATIVIDADES DE INVESTIMENTO DOS REGIMES 124

PRÓPRIOS DE PREVIDÊNCIA SOCIAL (RPPS) DOS MUNICÍPIOS DO ESTADO

DO RIO GRANDE DO SUL

As atividades de investimentos tratadas neste estudo referem-se às modalidades de investimentos praticadas pelos Regimes Próprios de Previdência Social (RPPS), estabelecidas pela Resolução 3.506/2007 editada pelo Conselho Monetário Nacional (CMN). De uma forma geral, pode-se dizer que existem diversas classes de investimentos em que os recursos dos fundos do RPPS, objeto deste estudo, podem ser aplicados. Mas há que se considerar que as decisões financeiras não são tomadas em ambientes de total certeza, uma vez que essas decisões são voltadas para o futuro. Dessa maneira, a condição de incerteza em que é tomada a decisão de aplicação de recursos deve induzir o gestor a adotar práticas adequadas de mensuração, controle e monitoramento dos riscos aos quais os investimentos estão expostos.

\subsubsection{Principais riscos associados aos investimentos financeiros dos fundos do RPPS}

Com o desenvolvimento da economia, houve um incremento dos instrumentos financeiros, que passaram a facilitar operações capazes de levar a uma aceleração do crescimento econômico. Tal fato requer uma administração de riscos eficaz, visto que, o foco da atividade financeira tem o risco como sua parte integrante. Torna-se oportuno, então, contextualizar, sucintamente, os principais tipos de riscos que envolvem os instrumentos financeiros dos RPPS, os quais se apresentam da seguinte forma:

a) Risco de Mercado: Para Marshall (2002), riscos de mercado são aquelas flutuações no lucro líquido ou no valor de carteira resultantes de mudanças de preços específicos de mercado (risco de taxas de juros, risco de capital, risco de câmbio, risco de commodity);

b) Risco de Crédito: É a possibilidade de perdas decorrentes da incapacidade de contrapartes cumprirem contratos mantidos com os fundos. Estão presentes em operações de crédito, empréstimos e financiamentos e em títulos e papéis representantes de operações financeiras ( $\mathrm{CDB}, \mathrm{CDI}$ etc) ou adquiridos no mercado (debêntures, letras, etc) quando são denominados riscos de emissor (FERNANDES, 2000).

c) Risco de Liquidez: Segundo Brito (2000, p. 70) o risco de liquidez "decorre da falta de caixa (recursos) necessária para honrar obrigações assumidas nas transações".

d) Risco Operacional: Para Marshall (2002) é o risco de falha dentro dos vários processos operacionais internos e estas falhas podem ocorrer em qualquer estágio do processo de agregação de valor através de erros de marketing, vendas, escrituração das transações, dentre outros.

e) Risco Legal: Para Jorion (2003) o risco legal está presente quando uma transação pode não ser amparada por lei. Os riscos legais são controlados por meio de políticas 
desenvolvidas pelo departamento jurídico da instituição. Cabe à instituição assegurar-se de que acordos entre contrapartes podem ser cumpridos antes que o negócio seja consumado.

Se existem diversos riscos inerentes aos investimentos financeiros dos fundos dos RPPS, então uma gestão de risco eficaz é fundamental para que estes fundos atendam às expectativas de compromissos previdenciários (superar passivos atuariais) e garantam a aposentadoria de seus contribuintes. Em outras palavras, deve haver uma política de investimentos dos fundos do RPPS capaz de promover a segurança dessas aplicações, de maneira a minimizar a incapacidade de atender as obrigações do regime de previdência.

\subsubsection{Os investimentos previstos pela Resolução n $3.506 / 2007$}

A Resolução $n^{\circ} 3.506$, editada pelo CMN em 26 de outubro de 2007, dispõe sobre as aplicações dos recursos dos regimes próprios de previdência social instituídos pela União, pelos Estados, pelo Distrito Federal ou por Municípios. Essa Resolução revogou a Resolução $\mathrm{n}^{\mathrm{o}} 3.244 / 2004$ e ampliou as oportunidades de investimentos para os RPPS. Seu objetivo é tornar a gestão cada vez mais eficaz e com isso fortalecer o patrimônio desses fundos para garantir condições de honrar os compromissos previdenciários sob a sua responsabilidade. Em outras palavras, maiores retornos vêm acompanhados de maiores riscos, o que exige melhores controles. A Resolução $\mathrm{n}^{\mathrm{o}} 3.506$ estabelece limites destinados justamente a manter sob controle os riscos financeiros dos RPPS.

A definição de limites de composição das carteiras de investimentos dos fundos do RPPS remete à preocupação de desenvolver estratégias e/ou mecanismos de proteção dos recursos desses fundos de riscos gerenciais e financeiros inerentes aos investimentos. $\mathrm{O}$ Quadro 2 apresenta os principais limites estabelecidos para a política de investimentos dos RPPS, com base na Resolução do CMN n ${ }^{\circ} 3.506 / 2007^{2}$.

\footnotetext{
${ }^{2}$ Alterados pela RESOLUÇÃO CMN No 3.790/2009, que estabelece:

Renda Fixa: Alterações para $30 \%$ em fundos de renda fixa sob a forma de condomínio aberto; até $5 \%$ (cinco por cento) em cotas de fundos de investimento em direitos creditórios, constituídos sob a forma de condomínio fechado;

Renda Variável: Alterações para até $20 \%$ (vinte por cento) em cotas de fundos de índices referenciados em ações, negociadas em bolsa de valores, admitindo-se exclusivamente os índices Ibovespa, IBrX e IBrX-50; até 15\% (quinze por cento) em cotas de fundos de investimento em ações, constituídos sob a forma de condomínio aberto; até 5\% (cinco por cento) em cotas de fundos de investimento classificados como multimercado; até 5\% (cinco por cento) em cotas de fundo de investimento em participações, constituídos sob a forma de condomínio fechado; até $5 \%$ (cinco por cento) em cotas de fundos de investimento imobiliário, com cotas negociadas na bolsa de valores;

Imóveis: Sem alterações

REAd - Edição 68, Volume 17, N 1, jan/abr 2011 - p. 117-148
} 
GESTÃO DE RISCO NAS ATIVIDADES DE INVESTIMENTO DOS REGIMES126

PRÓPRIOS DE PREVIDÊNCIA SOCIAL (RPPS) DOS MUNICÍPIOS DO ESTADO

DO RIO GRANDE DO SUL

\begin{tabular}{|c|c|c|}
\hline \multicolumn{3}{|c|}{ Resolução CMN no 3.506/2007 } \\
\hline RENDA FIXA & RENDA VARIÁVEL & IMÓVEIS \\
\hline $\begin{array}{l}\text { - Até } 100 \% \text { em títulos públicos federais } \\
\text { - Até } 80 \% \text { em cotas de investimentos } \\
\text { referenciados; } \\
\text { - } 20 \% \text { em Depósitos de Poupança; } \\
\text { - } 15 \% \text { em fundos de Renda fixa sob a } \\
\text { forma de condomínio aberto; } \\
\text { - } 15 \% \text { em fundos de direitos creditórios } \\
\text { sob a forma de condomínio aberto. }\end{array}$ & $\begin{array}{l}\text { - Até } 30 \% \text { em de fundos de } \\
\text { investimentos previdenciários } \\
\text { (classificados como ações); } \\
\text { - Até } 20 \% \text { em ações sob a forma de } \\
\text { condomínio aberto; } \\
\text { - Até } 3 \% \text { em fundos de investimentos } \\
\text { classificados como Multimercado. }\end{array}$ & $\begin{array}{l}\text { Terrenos e outros imóveis } \\
\text { vinculados por Lei ao RPPS, } \\
\text { mediante a integralização de } \\
\text { cotas de fundos de investimentos } \\
\text { imobiliários. }\end{array}$ \\
\hline
\end{tabular}

Quadro 2-Limites de Investimentos estabelecidos pela Resolução do CMN no 3.506/2007.

Fonte: Elaborado pelos autores.

Os limites de investimentos apresentados pela regulamentação de aplicação dos fundos dos RPPS (Resolução n ${ }^{\circ}$ 3.506/2007) acarretam a necessidade de controles gerenciais, em especial os concernentes à gestão de riscos, que permitam otimizar a eficiência na aplicação de recursos dentre as alternativas de investimentos disponíveis.

Diante do exposto, é notória a importância de se conhecer a forma ou estratégias que estão sendo utilizadas pelos gestores dos RPPS para minimizar os riscos existentes nas atividades de investimentos, estabelecidas pela Resolução no 3.506/2007. Para o atendimento do objeto proposto na pesquisa será apresentado, na sequência, o método utilizado para o desenvolvimento deste estudo.

\section{MÉTODO E PROCEDIMENTOS DE PESQUISA}

No tocante à população do estudo, elegeram-se os municípios do Estado do Rio Grande do Sul que possuem RPPS constituído. Segundo dados do Ministério da Previdência e Assistência Social - MPAS (2009) são 303 os municípios gaúchos que satisfazem a este critério. Destaca-se que todos os municípios pertencentes à população desta pesquisa receberam o instrumento de pesquisa (questionário) por meio eletrônico, sendo que 84 municípios responderam o questionário, aleatoriamente. Este número corresponde a uma amostra probabilística com $91 \%$ de confiança e com aceitação de um erro amostral de $9 \%$.

Com relação aos procedimentos de coleta de dados, têm-se para este estudo a pesquisa bibliográfica e por levantamento ou survey. Após a especificação do instrumento de coleta de dados realizou-se a identificação, através do sítio do MPAS, de todos os municípios do Estado do Rio Grande do Sul que possuíam RPPS legalmente constituído na data de 16 de dezembro de 2007. Na sequência, buscou-se no cadastro público do MPAS o endereço eletrônico dos representantes dos RPPS de cada município. A identificação foi feita da seguinte forma: na homepage do MPAS encontra-se um link onde é possível obter informações tais como as

REAd - Edição 68, Volume 17, No 1, jan/abr 2011 - p. 117-148 
contribuições mensalmente repassadas pelo município ao RPPS, saldos, número de servidores, alíquotas de contribuições, e outras (chamado de demonstrativo previdenciário). Além disso, também se encontram os nomes dos responsáveis pela gestão do RPPS com seus respectivos endereços eletrônicos. De posse dessa informação, acessaram-se todos os demonstrativos previdenciários dos 303 RPPS que constituem a população do estudo.

Uma vez coletados os endereços eletrônicos, providenciou-se o envio do questionário aos responsáveis via e-mail. A coleta de respostas foi realizada no período de dezembro de 2007 a fevereiro de 2008. De posse dos questionários respondidos, buscou-se organizar e tabular os dados de tal forma que pudessem produzir informações conclusivas, sustentando o problema proposto nesta pesquisa.

Finalmente, com a aplicação da técnica estatística denominada análise de clusters, ou análise de conglomerados ou ainda análise de agrupamentos, procedeu-se à análise dos dados coletados. Segundo Maroco (2003, p. 295), a análise de grupo ou de clusters "é uma técnica de análise multivariada que permite agrupar sujeitos ou variáveis em grupos homogêneos ou compactos relativamente a uma ou mais características comuns".

Como limitações desta pesquisa têm-se: a) embora existam aspectos dos municípios gaúchos que são comuns a outros estados, principalmente em relação à região sul do Brasil, as características da pesquisa não permitem fazer inferência para os RPPS de municípios fora do Rio Grande do Sul; b) a pesquisa tem como foco a gestão de riscos nas atividades de investimentos dos fundos do RPPS, em especial as atividades estabelecidas pela Resolução do CMN no 3.506/2007, não contemplando outros riscos a que esses fundos estão expostos; c) possibilidade do gestor do fundo, responsável pelas informações prestadas, não ter o devido conhecimento com relação à importância da gestão de riscos, uma vez que o gestor do fundo pode ser escolhido em assembleia, pelos próprios servidores municipais.

\section{ANÁLISE DOS DADOS}

Os RPPS estudados constituem uma forma de regime previdenciário que capta contribuições dos servidores públicos detentores de cargo efetivo e contribuições patronais do ente público instituidor. A alíquota de contribuição é fixada por Lei Municipal, sendo que aos servidores compete a alíquota de $11 \%$ sobre seus vencimentos, conforme estabelecido pela Lei $n^{\circ} 10.887$ de 18 de junho de $2004^{3}$ - (a partir dessa Lei, nenhum servidor contribui com

\footnotetext{
${ }^{3}$ Alterações estabelecidas na Lei $\mathrm{n}^{\circ} 11.941$ de 27 de maio de 2009 que trata da contribuição do Plano de Seguridade do Servidor Público - PSS

REAd - Edição 68, Volume 17, No 1, jan/abr 2011 - p. 117-148
} 
GESTÃO DE RISCO NAS ATIVIDADES DE INVESTIMENTO DOS REGIMES128

PRÓPRIOS DE PREVIDÊNCIA SOCIAL (RPPS) DOS MUNICÍPIOS DO ESTADO

DO RIO GRANDE DO SUL

alíquota inferior aos $11 \%$ estabelecidos). Já a contribuição patronal (da entidade pública) é fixada também por Lei Municipal, e seu valor é definido mediante a realização de cálculo atuarial, o qual estabelece a respectiva alíquota de contribuição para cada ente público.

O Estado do RS possui 183.868 servidores públicos municipais distribuídos entre ativos, inativos e pensionistas que participam de RPPS (BRASIL/MPAS, 2009). Os 303 RPPS municipais gaúchos possuem um montante de $\mathrm{R} \$ 2.205$ milhões em investimentos. Observa-se que se trata de um número significativo de contribuintes distribuídos entre esses fundos, que possuem um expressivo volume de recursos alocados entre as diversas modalidades de investimentos previstas na legislação vigente. As entidades pesquisadas encontram-se localizados em diversas regiões do estado, com diferentes tempos de constituição de seus regimes próprios (desde antes do ano de 2000 até fundos recentemente constituídos).

Acrescenta-se ainda que os RPPS estudados foram selecionados aleatoriamente a partir dos questionários respondidos. Assim sendo, não são revelados os nomes dos fundos, seus respectivos gestores e municípios a que pertencem. Apenas serão utilizados os dados obtidos de cada município, os quais serão tratados de forma conjunta e como reveladores de tendências.

\subsection{Características da Gestão dos RPPS}

Esta seção relata a forma como a gestão de recursos do RPPS é realizada e questiona a conduta dos gestores, ou seja, se a mesma está pautada em elevados padrões éticos e de integridade e voltados para a defesa dos direitos dos participantes destes fundos.

Na Tabela 1 têm-se os dados relativos à existência de código ética nos RPPS.

Tabela 1 - Existência de código de ética e conduta no fundo de pensão

\begin{tabular}{l|c|c}
\hline \multicolumn{1}{c|}{ Alternativa } & Frequência & \% \\
\hline Sim e próprio & 2 & 2,4 \\
\hline Sim, do município & 3 & 3,6 \\
\hline Não possui & 79 & 94 \\
\hline Total & $\mathbf{8 4}$ & $\mathbf{1 0 0}$ \\
\hline
\end{tabular}

Fonte: dados da pesquisa.

A Tabela 1 demonstra que 94\% dos RPPS não possuem nenhum código de ética e conduta, apenas 2,4\% possuem código próprio do fundo e 3,6.\% utilizam o mesmo código adotado pelo município. A principal função do código de ética e conduta é estabelecer princípios de responsabilidade, deveres e vedações como padrões de conduta, passando por questões comportamentais em ambiente de trabalho e aplicações financeiras de recursos REAd - Edição 68, Volume 17, No 1, jan/abr 2011 - p. 117-148 
particulares. Os padrões estabelecidos tem o intuito de buscar uma gestão socialmente responsável, com maior transparência por parte das instituições, tanto públicas quanto privadas, nas relações com fornecedores, servidores e cidadãos (Portaria da Secretaria do Tesouro Nacional - STN no 602/2005). Convém salientar que a formalização do código de ética e conduta também faz parte das obrigações dos gestores do RPPS e que foi estabelecido pela Resolução do CMN no 3.506/2007.

Considerando o exposto pela STN e pela Resolução vigente, a Tabela 1 apresenta dados que merecem atenção dos gestores dos fundos e por parte do MPAS, que é órgão responsável pela fiscalização dos RPPS, visto que $94 \%$ dos fundos entrevistados não apresentam código de ética e conduta formalizado.

A Tabela 2 apresenta dados referentes à gestão de aplicações dos recursos do RPPS, pois de acordo com a Resolução do $\mathrm{CMN} \mathrm{n}^{\circ} 3.506 / 2007$, ela pode ser própria, feita por entidade terceira credenciada ou mista.

Tabela 2 - Forma de Gestão quanto às aplicações dos fundos do RPPS.

\begin{tabular}{l|c|c}
\hline \multicolumn{1}{c|}{ Alternativa } & Frequência & \% \\
\hline Própria & 84 & 100 \\
\hline Gestão Terceirizada & 0 & 0 \\
\hline Mista & 0 & 0 \\
\hline Total & $\mathbf{8 4}$ & $\mathbf{1 0 0}$ \\
\hline
\end{tabular}

Fonte: dados da pesquisa.

Conforme dados constantes na Tabela 2, os respondentes foram unânimes com relação à gestão das aplicações dos fundos, ou seja, todos declararam serem responsáveis pela realização das aplicações financeiras de seus respectivos fundos. No entanto, salienta-se que a Resolução do CMN 3.506/2007 prevê que gestão das aplicações financeiras pode ser própria, terceirizada ou mista, desde que seja feito processo seletivo para credenciamento de terceiros.

A partir da informação de que $100 \%$ da gestão das aplicações financeiras são feitas pelos próprios gestores, a próxima seção apresenta os principais aspectos referentes à política de investimento que está sendo praticada pelos responsáveis pelos fundos do RPPS.

\subsection{A política de investimentos dos RPPS}

A política de investimentos dos RPPS diz respeito ao modelo de gestão a ser adotado. Em outras palavras, deve contemplar a estratégia de alocação dos recursos entre os diversos segmentos de aplicação e as respectivas carteiras de investimentos, observados os limites estabelecidos para cada modalidade de aplicação na legislação vigente. 
GESTÃO DE RISCO NAS ATIVIDADES DE INVESTIMENTO DOS REGIMES130

PRÓPRIOS DE PREVIDÊNCIA SOCIAL (RPPS) DOS MUNICÍPIOS DO ESTADO

DO RIO GRANDE DO SUL

Na sequência, utilizando-se dos dados coletados através do instrumento de pesquisa, apresentam-se informações sobre a política de investimentos que vem sendo praticada pelos RPPS investigados. Trata-se das 13 questões distribuídas na parte $\mathrm{B}$ do questionário (Apêndice 1) em que os gestores expressam, através do grau de concordância ou discordância, as respectivas políticas adotadas.

Para melhor compreensão dos dados, as análises estão expostas através de percentual (\%) acumulado, sendo que para a obtenção do (\%) acumulado de 1 para 5, somam-se os valores (\%) das alternativas 1, 2, 3, 4 e 5, respectivamente. Para o (\%) acumulado de 5 para 1 , somam-se as alternativas 5, 4, 3, 2 e 1, respectivamente. Dessa forma, têm-se os percentuais acumulados para "discordo" e "concordo", facilitando a análise dos resultados.

As assertivas utilizadas contemplam a existência e o conteúdo da política de investimentos do RPPS, considerando os requisitos da Resolução do CMN n 3.506/2007. Além disso, são feitos questionamentos com relação aos seguintes tópicos: (i) à acessibilidade à política por parte dos servidores participantes do RPPS, (ii) limites de concentração de investimentos em determinados intermediários financeiros, (iii) parâmetros a serem adotados para cálculo dos níveis de exposição a riscos, (iv) limites de risco aprovados, (v) padrões e procedimentos para acompanhamento dos ratings das instituições que recebem ou administram recursos, (vi) necessidade de segregação de função entre os responsáveis pelas operações de investimentos e os responsáveis pelo processamento dos documentos, (vii) responsabilidades sobre a escolha de alternativas de investimentos, (viii) definição prévia de limites de crédito a serem observados na condução de negócios com cada intermediário financeiro, (ix) consequências das violações da política de investimentos por parte dos gestores, (x) participação de pessoas com conhecimentos técnicos especializados em gestão de investimentos na elaboração e revisão da política, e, finalmente, (xi) se os limites de investimento estabelecidos nas normas do RPPS permitem uma diversificação adequada nos investimentos da entidade.

A Figura 1 apresenta a média para todos os respondentes entrevistados, com relação à política de investimentos adotada, com base nas 13 questões utilizadas. Sua leitura mostra que $58 \%$ declaram não possuir uma política de investimentos implementada, seguindo de 30,5\% que afirmam possuir uma política e 11,5\% que não demonstraram se a política existe ou não.

A partir dos dados apresentados na Figura 1 pode-se evidenciar, de uma forma geral, que a grande maioria não possui a política de investimentos formalizada. Sendo que os gestores responsáveis pelos investimentos destes fundos, talvez por não disporem de pessoas

REAd - Edição 68, Volume 17, No 1, jan/abr 2011 - p. 117-148 
com conhecimento técnico adequado, preocupam-se, basicamente, em atender aos requisitos mínimos estabelecidos pela Resolução do CMN nº 3.506/2007 no tocante aos enquadramentos estabelecidos na diversificação dos investimentos, não priorizando critérios de transparência, gestão de risco-retorno e responsabilidade dos gestores.

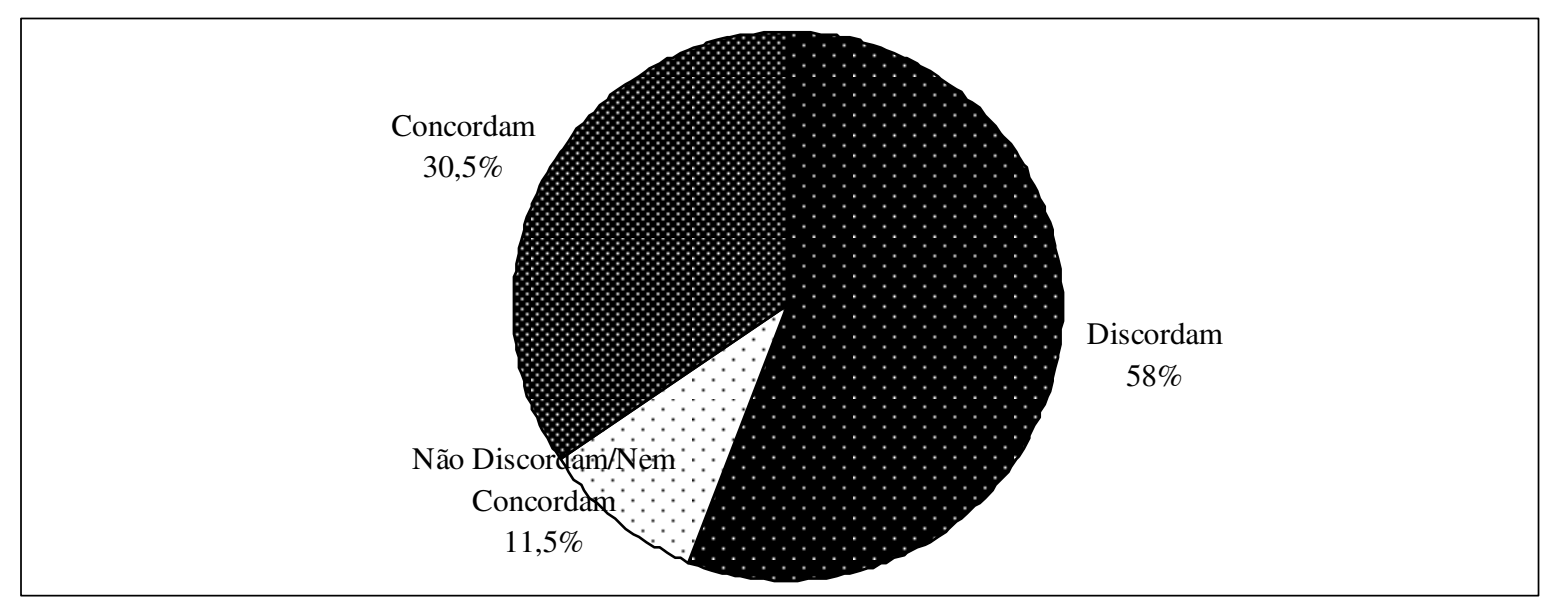

Figura 1 - Média apresentada pelos RPPS com relação a Política de Investimentos Fonte: Dados da pesquisa

Observou-se ainda que a grande maioria dos gestores conhece as exigências previstas na Resolução do $\mathrm{CMN}$ n$^{\circ}$ 3.506/2007 no tocante à política de investimentos. Mesmo assim, preocupam-se, basicamente, em atender aos requisitos mínimos estabelecidos com relação aos enquadramentos estabelecidos na diversificação dos investimentos, não priorizando critérios de transparência, gestão de risco-retorno e responsabilidade dos gestores.

\subsection{Práticas de gestão de investimentos exercidas pelos RPPS}

As práticas de gestão de investimentos dos RPPS dizem respeito a ações implementadas pelos gestores responsáveis pelos fundos, ou seja, referem-se aos procedimentos efetivamente adotados pelos RPPS na condução quotidiana das atividades de investimento. Trata-se, portanto, de verificar se os procedimentos adotados são adequados, independentemente da situação verificada na formalização das políticas.

Com o intuito de atingir o objetivo desta seção, demonstram-se os resultados de 5 questões, distribuídas na parte $\mathrm{C}$ do questionário empregado (Apêndice 1), em que os gestores expressam, por meio do grau de concordância ou discordância, as respectivas práticas adotadas em cada RPPS. As questões utilizadas para investigar as práticas de gestão de investimentos dos RPPS foram: (i) existência de mecanismos de checagem da execução das transações de investimentos com os parâmetros definidos nas políticas e normas existentes sobre o assunto, (ii) existência de monitoramento adequado para políticas e procedimentos REAd - Edição 68, Volume 17, No 1, jan/abr 2011 - p. 117-148 
GESTÃO DE RISCO NAS ATIVIDADES DE INVESTIMENTO DOS REGIMES132

PRÓPRIOS DE PREVIDÊNCIA SOCIAL (RPPS) DOS MUNICÍPIOS DO ESTADO

DO RIO GRANDE DO SUL

adotados, (iii) existência de parâmetros e regras que previnam conflitos de interesses de todos os profissionais envolvidos na execução dos negócios, (iv) existência de regras escritas para orientar o relacionamento com os gestores, custodiantes e corretores, e (v) existência de bom nível de segregação de funções entre o pessoal da linha de operação e o pessoal da linha de controle (confirmação, reconciliação etc.) e de liquidação (desembolso de valores e liquidação financeira de operações).

Para analisar o objetivo proposto nesta seção, a Figura 2 apresenta a média apresentada pelos RPPS no tocante a práticas de gestão de investimentos. Conforme dados constantes na Figura, 70\% asseguram não existir práticas de gestão de investimentos. 14\% asseguram existir e 16\% não declararam se as práticas de gestão existem ou não.

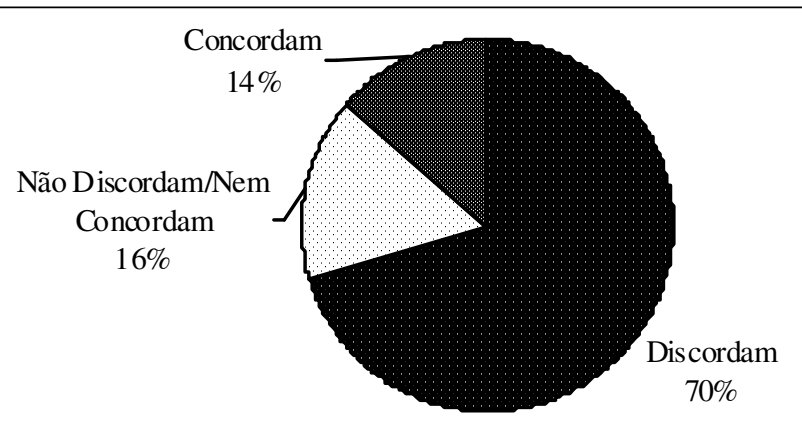

Figura 2 - Média apresentada pelos RPPS com relação a Práticas de Gestão de Investimentos Fonte: Dados da pesquisa

É importante salientar que embora alguns gestores tenham declarado a efetiva existência de práticas de gestão de investimentos dos fundos dos RPPS, verificou-se a grande maioria assegura não existir tais práticas. Trata-se de uma constatação relevante, uma vez que a inexistência de mecanismos de controle e de monitoramento por parte dos gestores dos fundos pode comprometer a segurança, a rentabilidade e a transparência dos RPPS. Também é importante observar, que embora a Resolução do CMN n 3.506/2007 represente um avanço com relação ao estabelecimento de regras, limites, controles, gerenciamento de riscos, dentre outros, é importante assegurar que esses mecanismos sejam realmente cumpridos pelos gestores dos RPPS. Portanto, cabe ao MPAS proceder a uma fiscalização efetiva.

\subsection{Sistemas de Apoio à gestão de investimentos}

Os sistemas de apoio à gestão de investimentos referem-se ao conjunto de ferramentas, métodos e técnicas utilizados pelos gestores dos RPPS na execução da política de investimentos. Com o intuito de atingir o objetivo desta seção, demonstram-se os resultados de 4 questões, distribuídas na parte D do questionário empregado (Apêndice 1), em que os gestores expressam, por meio do grau de concordância ou discordância, os respectivos REAd - Edição 68, Volume 17, No 1, jan/abr 2011 - p. 117-148 
sistemas de apoio à gestão adotada. As questões utilizadas para investigar os sistemas de apoio à gestão utilizados foram: (i) utilização pelo RPPS de modelos quantitativos formais para definir limites dos riscos, (ii) existência de mecanismos de controle de adequação dos níveis de investimentos aos limites determinados com base nos modelos quantitativos, e (iii) existência de informação gerencial suficientemente compreensiva para a gestão de riscos de investimentos.

Conforme dados expostos na Figura 3, 74\% dos gestores dos RPPS não utilizam sistemas de apoio à gestão de investimentos, seguidos de $11 \%$ que declaram utilizar sistemas de apoio e $15 \%$ que não manifestaram a utilização ou não de sistemas de apoio à gestão.

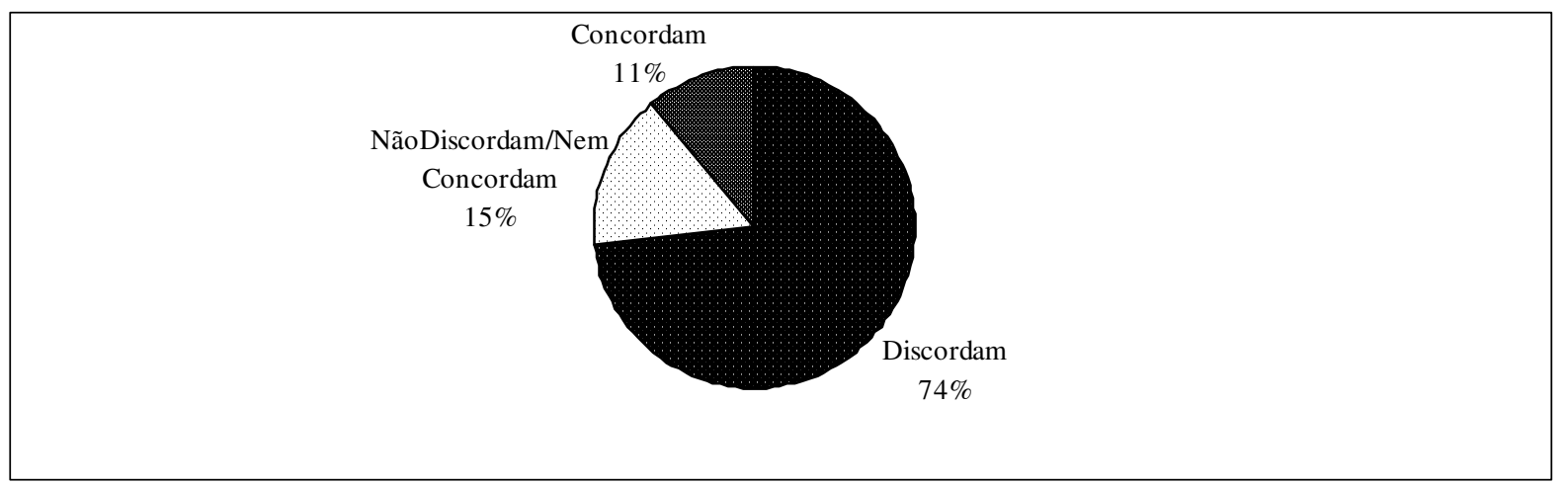

Figura 3 - Média apresentada pelos RPPS com relação ao Sistema de Apoio à Gestão de Investimentos Fonte: Dados da pesquisa

São dados que merecem atenção, pois a relação risco-retorno, bem como os limites de investimentos estabelecidos pela Resolução do CMN no 3.506/2007, implicam na necessidade de construção de modelos gerenciais quantitativos, que permitam otimizar a eficiência na aplicação dos recursos entre as alternativas de investimentos disponíveis. Na visão de Boulier e Dupré (2003), os modelos de otimização são fundamentais para o desenvolvimento de níveis eficientes de aplicação de recursos na consolidação de carteiras de investimentos de fundos previdenciários.

Para finalizar a análise sobre os sistemas de apoio à gestão de investimentos, investigou-se a seguinte informação: caso sua entidade possua empresa credenciada para a gestão de recursos do RPPS, essa empresa fornece informações sobre a rentabilidade e o risco das aplicações? Como nenhum dos entrevistados respondeu a questão, subentende-se que os RPPS não possuem empresas credenciadas para a gestão de recursos, o que vem ao encontro da informação fornecida pelos respondentes quando perguntado se a gestão dos fundos dos RPPS era própria, terceirizada ou mista, quando todos foram unânimes em responder que a gestão é própria.

REAd - Edição 68, Volume 17, No 1, jan/abr 2011 - p. 117-148 
GESTÃO DE RISCO NAS ATIVIDADES DE INVESTIMENTO DOS REGIMES134

PRÓPRIOS DE PREVIDÊNCIA SOCIAL (RPPS) DOS MUNICÍPIOS DO ESTADO

DO RIO GRANDE DO SUL

A Figura 4 apresenta os métodos de controle de riscos utilizados pelos gestores dos RPPS e, como se pode visualizar, 55\% dos respondentes declaram não utilizar nenhum método para controle riscos, $23 \%$ afirmam utilizar outros métodos e consideram o cálculo atuarial como um método de controle. Contudo, é importante destacar que a Legislação prevê que (Lei 9.717/98, Portaria 4992/99 e Portaria 172/05), anualmente, os RPPS informem o Demonstrativo de Resultado de Avaliação Atuarial (DRAA). Logo, é de caráter obrigatório.

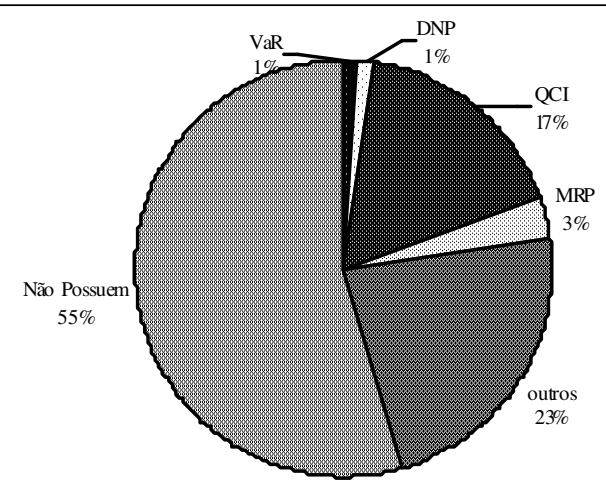

Figura 4- Métodos de Controle de Ricos Utilizados pelos RPPS Fonte: Dados da pesquisa

Prosseguindo-se a análise de acordo com o exposto na Figura 4, observa-se que somente $17 \%$ afirmam elaborarem questionários de controle interno (QCIs) que são ferramentas de direcionamento que auxiliam os gestores na implementação das melhores práticas no desempenho de suas funções e 3\% dos respondentes declaram realizar a marcação de riscos nos processos (MRP). É importante observar que somente $1 \%$ dos respondentes afirmam utilizar o VaR (Valor em Risco - Value at Risk) e a DNP (divergência não planejada- Tracking error).

Outra informação digna de nota é a de que um grande número de gestores entrevistados declara que as aplicações nas quais seus fundos encontram-se enquadrados são de baixo risco. Por esta informação, subentende-se que a grande maioria aplica os recursos do RPPS em renda fixa sob a forma de títulos públicos. Em outras palavras, enquadram-se na modalidade e nos limites previstos na Resolução do CMN no 3.506/2007, mesmo que esta Resolução apresente várias opções de investimentos que possam trazer maiores retornos.

O objetivo destas seções foi realizar a análise descritiva dos dados obtidos na pesquisa. Para tanto, os dados foram analisados em blocos de questões, distribuídas em 4 etapas (partes $\mathrm{A}, \mathrm{B}, \mathrm{C}$ e D), por meio das quais buscou-se compreender aspectos ligados a política de investimentos que vem sendo praticada pelos responsáveis pelos RPPS no Rio Grande do Sul. 
Os aspectos que envolvem a política de investimentos aqui tratados são os expostos por Fabozzi (2000), ou seja, o foco consiste em determinar estratégias de financiamentos de passivos pela seleção de ativos, de modo que os fluxos de caixa desses investimentos sejam iguais ou superiores aos das obrigações. Em outras palavras, constatar a forma como os gestores estão conduzindo as políticas de investimentos dos fundos do RPPS, de tal forma a garantir, rentabilidade, solvência, liquidez, transparência e equilíbrio financeiro e atuarial.

Assim sendo, pode-se observar, de uma forma geral, que a grande maioria dos RPPS entrevistados não possui a política de investimentos formalizada e que os gestores responsáveis pelos investimentos destes fundos, talvez por não disporem de pessoas com conhecimento técnico adequado, preocupam-se, basicamente, em atender aos requisitos mínimos estabelecidos pela Resolução do CMN n ${ }^{\circ} 3.506 / 2007$ no tocante aos enquadramentos estabelecidos na diversificação dos investimentos, limitando-se a aplicar os recursos dos fundos em modalidades de baixo risco, sacrificando assim rentabilidade e desempenho. Acrescenta-se ainda que um grande número de gestores responsáveis pelos RPPS não possui documentação formalizada capaz de auxiliá-los na tomada de decisões e, ao mesmo tempo, produzir as informações relevantes aos contribuintes destes fundos e promover a devida transparência que lhe compete.

Um aspecto positivo evidenciado é que alguns gestores declararam que estão implementando a política de investimento, com todas as formalizações legais que a Resolução do CMN no 3.506/2007 prevê. Portanto, cabe ao Ministério da Previdência Social promover as devidas instruções e uma fiscalização efetiva, para que essas políticas realmente atendam à legislação.

É salutar evidenciar que a legislação vigente vem apresentando avanços com relação à formalização e práticas que devem ser consideradas na ocasião da elaboração de uma política de investimentos eficiente e capaz de apresentar resultados que auxiliem os gestores dos RPPS. No entanto, essa observação não se estende às práticas encontradas nos respectivos fundos. Mesmo que a Resolução do $\mathrm{CMN} \mathrm{n}^{\mathrm{o}} 3.506 / 2007$ tenha estabelecido o prazo de 31 de dezembro de 2008 para que os RPPS se enquadrem nas referidas normas, a Resolução anterior (3.244/2004) já previa a formalização, as práticas e a mensuração que uma política de investimentos deveria contemplar. Portanto, as políticas e práticas encontradas estão muito aquém do previsto na teoria e na própria legislação.

Como foi observado nas análises apresentadas, existem alguns regimes que apresentam alguns aspectos relacionados à formalização de uma política de investimentos, 
GESTÃO DE RISCO NAS ATIVIDADES DE INVESTIMENTO DOS REGIMES136

PRÓPRIOS DE PREVIDÊNCIA SOCIAL (RPPS) DOS MUNICÍPIOS DO ESTADO

DO RIO GRANDE DO SUL

bem como as práticas, os métodos e técnicas de apoio à gestão de investimentos. Nesse sentido, por meio da utilização da técnica estatística de análise de clusters, evidenciam-se as características semelhantes que esses RPPS possuem.

\subsection{Análise de clusters aplicada aos RPPS}

A análise de clusters ou análise de agrupamentos é aplicada para verificar, dentre os 84 RPPS pesquisados e com base no questionário aplicado, quais são semelhantes entre si, ou ainda, as características comuns em cada grupo estabelecido, formando assim, agrupamentos de regimes próprios.

Segundo Hair Jr. et al. (2005, p. 384), “análise de agrupamentos é o nome para um grupo de técnicas multivariadas cuja finalidade primária é agregar objetos com base nas características que eles possuem". Esse tipo de análise classifica objetos, neste caso, os respondentes, de modo que cada RPPS possua semelhança em relação a algum critério de seleção predeterminado.

Com a utilização desta técnica estatística, faz-se uma análise dentre os RPPS pesquisados, com o objetivo de evidenciar semelhanças em relação às práticas de gestão de riscos nas atividades de investimentos que vêm sendo utilizadas pelos gestores destes fundos.

Para a elaboração dos clusters selecionou-se algumas características baseadas no instrumento de pesquisa utilizado, dentre as quais:

a) população do município, coletada da Contagem de População 2006 (IBGE, 2007);

b) quantidade de servidores participantes do RPPS;

c) ano de constituição do regime;

d) montante de recursos aplicados;

e) transparência de gestão, definida em função da divulgação aos servidores participantes da política e de informações sobre os investimentos; e

f) disponibilidade de pessoas com conhecimento técnico especializado para auxiliar na elaboração de políticas de investimentos.

Estabeleceu-se a formação dos Clusters pela distância média entre eles (Average Linkage Between Groups), visualmente verificada no Dendrograma representado na Figura 5. Com a utilização do programa SPSS versão 11.5, calculou-se os agrupamentos hierárquicos, formadores dos clusters, utilizando-se da medida de distância Euclidiana, que de acordo com Maroco (2003), é a medida mais comumente usada da similaridade entre dois objetos por dimensionar as observações correspondentes aos indivíduos. 


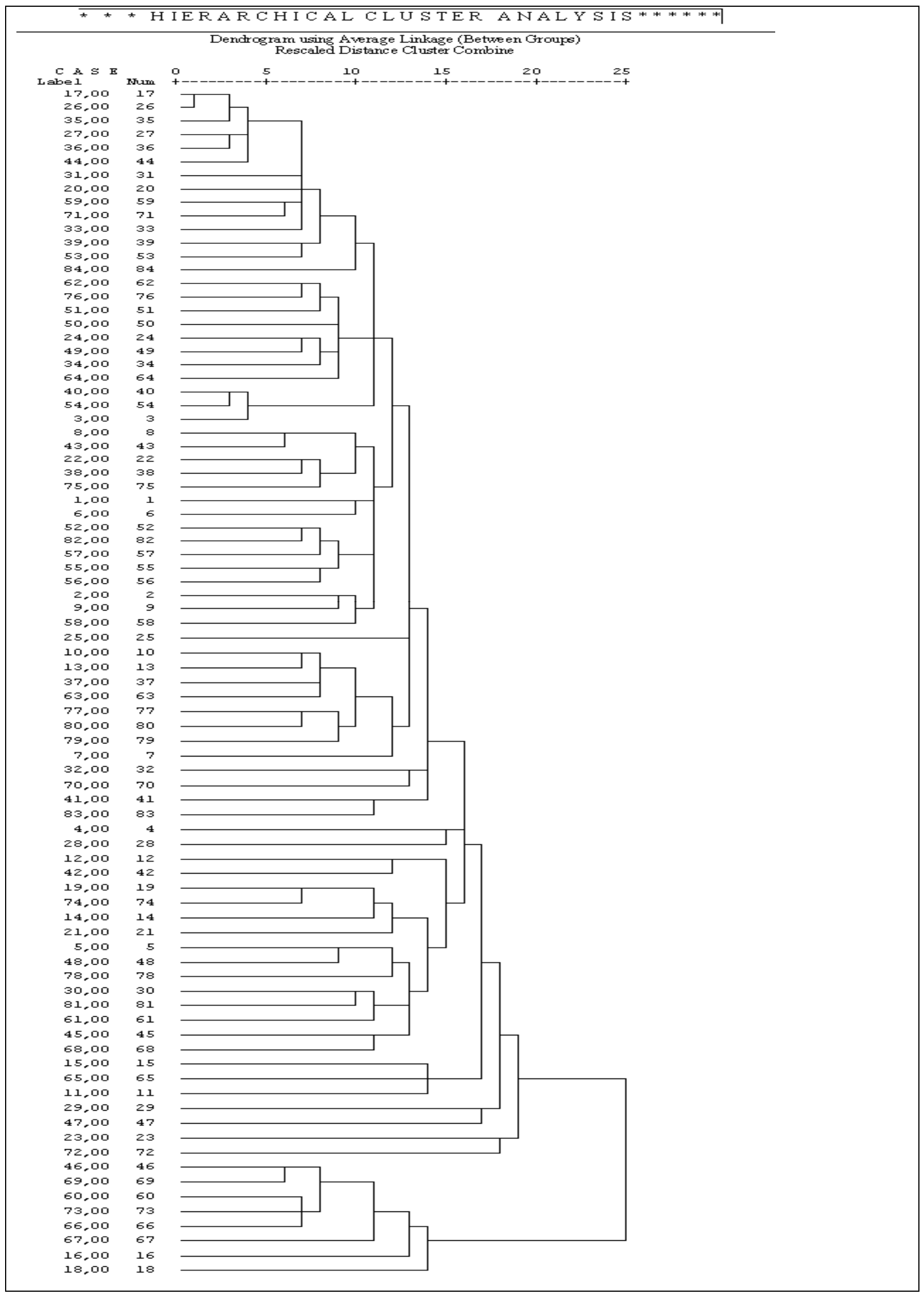

Figura 5 - Agrupamento hierárquico dos RPPS

Fonte: dados da pesquisa.

REAd - Edição 68, Volume 17, Nº 1, jan/abr 2011 - p. 117-148 
GESTÃO DE RISCO NAS ATIVIDADES DE INVESTIMENTO DOS REGIMES138

PRÓPRIOS DE PREVIDÊNCIA SOCIAL (RPPS) DOS MUNICÍPIOS DO ESTADO

DO RIO GRANDE DO SUL

A Figura 5 apresenta a formação de 3 clusters referentes aos dados dos RPPS pesquisados, com relação à política de investimentos, às práticas de gestão de riscos nas atividades de investimentos e à utilização de sistemas de apoio à gestão de investimentos dos RPPS. A partir do Dendrograma, foram identificados os casos (municípios e seus respectivos RPPS) pertencentes aos clusters formados, bem como, as características semelhantes apresentadas pelos respectivos casos. Convém destacar que os municípios e seus respectivos RPPS, estão sendo tratados como "casos" e identificados por números, preservando a identidade de cada um.

Para melhor visualização, os clusters formados e suas respectivas características, encontram-se sintetizadas no Quadro 3.

\begin{tabular}{|c|c|c|c|}
\hline Características & Cluster 1 & Cluster 2 & Cluster 3 \\
\hline $\begin{array}{l}\text { Casos correspondentes } \\
\text { (municípios e seus RPPS). }\end{array}$ & $\begin{array}{l}\text { 1- 2- 3- 4-5- 6- 7- 8- 9- 10- 11- } \\
\text { 12- 13- 14- 15- 17- 19- 20- 21- } \\
\text { 22- 24- 25- 26- 27- 28- 29- 30- } \\
\text { 31- 32-33- 34- 35- 36- 37- 38- } \\
\text { 39- 40- 41- 42- 43- 44- 45- 47- } \\
\text { 48- 49- 50- 51- 52- 53- 54- 55- } \\
\text { 56- 57- 58- 59- 61- 62- 63- 64- } \\
\text { 65- 68- 70- 71- 74- 75- 76- 77- } \\
78-79-80-81-82-83-84\end{array}$ & $\begin{array}{l}16-18-46-60- \\
66-67-69 \text { e } 73\end{array}$ & 23 e 72 \\
\hline Tamanho do município. & $\begin{array}{l}\text { Pequenos municípios, a grande } \\
\text { maioria com até } 30 \text { mil } \\
\text { habitantes. }\end{array}$ & $\begin{array}{l}\text { A grande maioria } \\
\text { dos Municípios } \\
\text { possui população } \\
\text { acima de } 30 \text { mil } \\
\text { habitantes. }\end{array}$ & $\begin{array}{l}\text { A maior parte dos } \\
\text { municípios possui } \\
\text { população acima de } \\
100 \text { mil habitantes. }\end{array}$ \\
\hline $\begin{array}{l}\text { Servidores municipais } \\
\text { participantes do RPPS } \\
\text { (ativos, inativos e } \\
\text { pensionistas). }\end{array}$ & Até 1.000 servidores. & $\begin{array}{l}\text { Acima de } 1.000 \\
\text { servidores. }\end{array}$ & $\begin{array}{l}\text { Acima de } 3.500 \\
\text { servidores. }\end{array}$ \\
\hline $\begin{array}{l}\text { Ano de constituição do } \\
\text { RPPS. }\end{array}$ & $\begin{array}{l}\text { A maioria foi constituída após o } \\
\text { ano de } 2.000 .\end{array}$ & $\begin{array}{l}\text { A maioria foi } \\
\text { constituída antes } \\
\text { do ano de } 2.000 .\end{array}$ & $\begin{array}{l}\text { A maioria foi } \\
\text { constituída antes do } \\
\text { ano de } 2.000 .\end{array}$ \\
\hline $\begin{array}{l}\text { Possui pessoas com } \\
\text { conhecimento técnico } \\
\text { especializado que auxiliem } \\
\text { na elaboração da política de } \\
\text { investimentos dos RPPS. }\end{array}$ & Não possuem. & $\begin{array}{l}\text { A grande maioria } \\
\text { possui. }\end{array}$ & Todos possuem. \\
\hline $\begin{array}{l}\text { Montante de recursos } \\
\text { aplicados. }\end{array}$ & Até R\$ 5 milhões. & $\begin{array}{l}\text { Acima de } \mathrm{R} \$ 20 \\
\text { milhões. }\end{array}$ & $\begin{array}{l}\text { Acima de R } \$ 70 \\
\text { milhões. }\end{array}$ \\
\hline $\begin{array}{l}\text { Transparência apresentada na } \\
\text { gestão praticada nos RPPS. }\end{array}$ & Praticamente não existe. & $\begin{array}{l}\text { A grande maioria } \\
\text { apresenta. }\end{array}$ & Há transparência. \\
\hline
\end{tabular}

Quadro 3 - Síntese das semelhanças dos RPPS do Rio Grande do Sul

Fonte: elaborado pelos autores a partir dos dados da pesquisa.

Estes casos formam o primeiro cluster e possuem as seguintes características semelhantes: regimes próprios correspondentes a municípios com população inferior a 30 mil habitantes; em geral o fundo foi constituído a partir do ano de 2000 (fundos de formação recente); os RPPS possuem até 1.000 participantes (ativos, inativos e pensionistas); não REAd - Edição 68, Volume 17, No 1, jan/abr 2011 - p. 117-148 
possuem pessoa com conhecimento técnico especializado que auxilie na elaboração de políticas de investimentos e a grande maioria dos participantes desconhece as políticas de investimentos praticadas por seus gestores, uma vez que essas não estão acessíveis a todos os participantes. Tais características tornam esses RPPS vulneráveis com relação às práticas de gestão de riscos, ou seja, a gestão de riscos praticamente não existe.

O segundo cluster possui as seguintes características: referem-se aos RPPS implementados ainda na década de 1990, a grande maioria pertence a municípios de médio porte (acima de 30 mil habitantes), com mais de 1.000 participantes do regime, a grande maioria possui pessoa com conhecimento técnico especializado que participa na elaboração das políticas de investimentos e declaram que a política de investimentos está acessível a todos os participantes, demonstrando que esses regimes já vêm apresentando um aumento no nível de transparência da gestão dos fundos de pensão. Tais características comprovam que esses regimes aplicam algumas práticas de gestão de risco e demonstram saber da importância de se elaborar uma política de investimentos condizente com a legislação e capaz de fornecer aos seus gestores informações que permitam tomar melhores decisões.

Por fim, o terceiro cluster, cujas características identificadas são: pertencem a municípios de grande porte (acima de 100 mil habitantes), possuem acima de 3.500 participantes no RPPS, o montante de recursos aplicados está acima de R \$ 70milhões, todos afirmaram que possuem pessoas com conhecimento técnico especializado que auxiliam na elaboração de melhores práticas de gestão dos fundos e todos declararam que a política de investimentos praticada é de conhecimento dos participantes destes fundos.

A partir das características sintetizadas no Quadro 3, tem-se que os municípios menores formaram o primeiro cluster, em que as práticas de gestão de investimentos são quase inexistentes, tornando esses RPPS os mais frágeis. O segundo cluster é formado por municípios médios e que apresentam uma política que busca se enquadrar nas normas estabelecidas pela Resolução CMN no 3.506/2007. O terceiro e último cluster, é formado pelos municípios de grande porte e que possuem um montante de recursos superior a $\mathrm{R} \$ 70$ milhões, e principalmente, que na elaboração da política de investimentos e das práticas de gestão, participam pessoas com conhecimento técnico relacionado. É no terceiro cluster que se encontram as melhores práticas de gestão de riscos nos RPPS pesquisados. 
GESTÃO DE RISCO NAS ATIVIDADES DE INVESTIMENTO DOS REGIMES140

PRÓPRIOS DE PREVIDÊNCIA SOCIAL (RPPS) DOS MUNICÍPIOS DO ESTADO

DO RIO GRANDE DO SUL

\section{CONCLUSÕES E RECOMENDAÇÕES}

É notória a relevância que as entidades previdenciárias dedicadas ao funcionalismo público, aqui tratadas como RPPS, possuem no âmbito da sociedade, seja pelo alcance social no campo previdenciário ou pelo papel que exercem no ambiente econômico. Assim, caracterizando-se como fundos de pensão, a falta de mecanismos de controle de riscos torna essas entidades suscetíveis à baixa rentabilidade, comprometendo a manutenção da liquidez, da solvência e o equilíbrio econômico e atuarial dos planos de benefícios. Partindo-se dessa premissa, esta pesquisa teve por objetivo avaliar os mecanismos de controle de riscos que estão sendo adotados pelos gestores dos RPPS, nas atividades de investimento, como forma de garantir a proteção e o equilíbrio financeiro e atuarial.

Em relação ao primeiro objetivo específico, os RPPS foram caracterizados segundo a localização, número de servidores (ativos, inativos e pensionistas), pelo montante de recursos disponíveis, pela forma de gestão empregada na aplicação dos recursos e pela apresentação de código de ética e conduta. Assim, verificaram-se os RPPS localizados no Rio Grande do Sul, os quais são responsáveis pelas aposentadorias e pensões de servidores públicos municipais detentores de cargo público efetivo e que os mesmos possuem um significativo volume de recursos financeiros.

Com relação à gestão de investimentos praticada, observou-se que todos os gestores dos RPPS consultados são os responsáveis pelas aplicações financeiras de seus respectivos fundos, não existindo gestão terceirizada ou mista. Outra característica encontrada diz respeito ao código de ética e conduta em que o percentual de fundos que não possuem este código formalizado é de $94 \%$.

No que concerne ao segundo objetivo específico, de identificar a política de investimentos praticada pelos gestores dos fundos dos RPPS, constatou-se que, mesmo que, alguns gestores declaram possuir uma política de investimentos condizente com a política estabelecida pela Resolução do CMN n $3.506 / 2007$, 58\% dos gestores declaram que sua política não satisfaz aos requisitos previstos nesta Resolução.

Verificou-se ainda, com base nos dados pesquisados, que a política de investimentos praticada pelos gestores dos RPPS, responsáveis pelos investimentos destes fundos, por não disporem de pessoas com conhecimento técnico adequado, preocupam-se, basicamente, em atender aos requisitos de enquadramentos e limites estabelecidos na diversificação dos investimentos, não priorizando critérios de transparência, gestão de risco-retorno e a responsabilidade destes gestores para com os contribuintes.

REAd - Edição 68, Volume 17, No 1, jan/abr 2011 - p. 117-148 
Quanto ao terceiro objetivo específico, em que se buscou analisar as práticas de gestão de investimentos que estão sendo adotadas pelos RPPS para aumentar as condições de segurança, rentabilidade e transparência, verificou-se, com base nos dados pesquisados, uma média de 70\% de gestores dos RPPS que não adotam práticas de gestão de investimentos em seus respectivos fundos. Este resultado reflete a inexistência de mecanismos de controle e de monitoramento das atividades de investimentos realizadas por esses gestores, comprometendo a segurança, a rentabilidade e o equilíbrio financeiro e atuarial destes fundos.

Em relação ao quarto objetivo específico, em que se propôs analisar quais sistemas de apoio à gestão de investimentos que estão sendo adotados pelos gestores dos RPPS, evidenciou-se, por ocasião da pesquisa, que praticamente não são adotados métodos e técnicas de apoio à gestão, refletindo-se na média encontrada, ou seja, 74\% não possuem métodos de controles de riscos, de limites, de rentabilidade para os investimentos financeiros dos RPPS.

Outra informação digna de nota é a de que um grande número de gestores declarou que as aplicações financeiras nas quais seus fundos encontram-se enquadrados são de baixo risco. Por esta informação, subentende-se que a grande maioria aplica os recursos do RPPS em renda fixa sob a forma de títulos públicos, que são modalidades que apresentam menor risco. Em outras palavras, enquadra-se na modalidade e limite previstos na Resolução do CMN n 3.506/2007, mesmo que essa Resolução apresente várias opções de investimentos que possam trazer maiores retornos, caracterizando os gestores como avessos a risco (perfil conservador).

Quanto ao quinto objetivo específico, propôs-se por meio da análise de agrupamentos, avaliar o grau de distanciamento existente nas práticas de gestão de riscos executadas nos RPPS do Rio Grande do Sul, em que se constatou a formação de 3 clusters. No primeiro cluster encontram-se os RPPS cuja política de investimentos, práticas de gestão e mecanismos de controle de risco não existem. Como participantes do primeiro cluster tem-se os municípios com até 30 mil habitantes, com investimentos de até $\mathrm{R} \$ 5$ milhões, que possuem até 1.000 participantes no regime próprio, onde não participam pessoas com conhecimento técnico especializado na elaboração da política de investimentos, os fundos foram constituídos a partir do ano de 2000 e há pouca divulgação da política praticada pelos gestores dos RPPS aos participantes.

O segundo cluster é formado pelos RPPS que apresentam uma política que busca se enquadrar nas normas estabelecidas pela Resolução CMN no 3.506/2007. Os participantes deste cluster são os municípios médios (acima de 30 mil habitantes), com investimentos 
GESTÃO DE RISCO NAS ATIVIDADES DE INVESTIMENTO DOS REGIMES142

PRÓPRIOS DE PREVIDÊNCIA SOCIAL (RPPS) DOS MUNICÍPIOS DO ESTADO

DO RIO GRANDE DO SUL

acima de R \$ 20 milhões, possuem acima de 1.000 participantes no regime próprio, a grande maioria possui pessoas com conhecimento técnico especializado que participa da elaboração da política de investimentos, os fundos foram constituídos ainda na década de 1990 e a maior parte deles possui a política de investimentos amplamente divulgada.

No terceiro e último cluster é onde se encontram as melhores práticas de gestão de riscos nos RPPS pesquisados. Os RPPS participantes deste cluster são municípios com população acima de 100 mil habitantes, com investimentos superiores a R\$ 70 milhões, possuem acima de 3.500 participantes no regime, todos possuem a participação de pessoas com conhecimento técnico especializado na elaboração da política de investimentos, os fundos foram constituídos na década de 1990 e a política de investimento é amplamente divulgada aos participantes.

Conclui-se, com base nos dados produzidos pela pesquisa que, apesar da legislação vigente apresentar avanços com relação à formalização e práticas que devem ser consideradas na ocasião da elaboração de uma política de investimentos eficiente e capaz de apresentar resultados que auxiliem os gestores dos RPPS, os resultados da pesquisa demonstram que não são adotados mecanismos de controle de riscos para as atividades de investimentos. A inoperância das políticas de investimentos que vem sendo praticadas com relação aos limites de concentração de investimentos, limites de riscos (de mercado, crédito e liquidez), limites de créditos com cada intermediário financeiro, consequiências das violações da política de investimentos e nível de transparência, entre outros, pode comprometer a busca de rentabilidade e solvência dos RPPS. Tais resultados são consistentes com os obtidos nos estudos anteriores comentados na sequência.

Os estudos de Bodie (1988), Garcia (2003), Helbronner (2005) e Yermo (2008), já apontaram a importância da diversificação das carteiras, da busca por melhores patamares de rentabilidade, bem como do acompanhamento da performance da carteira de investimentos por parte de seus gestores. Cada um desses pesquisadores, no contexto de suas pesquisas, entatiza o estabelecimento de boas práticas de governança como forma de garantir melhor performance, liquidez e solvência dos fundos de pensão. A análise cruzada de resultados com o presente estudo caracteriza uma urgência na adoção de melhores políticas de investimento por parte dos RPPS brasileiros.

Herranz (1995), Gulias Júnior (2005) e Ferreira (2006) também apontaram a necessidade de delimitar percentuais máximos de alocação dos investimentos, como padrão de segurança, além de se observar o nível de exposição a riscos de mercado, crédito, entre 
outros. Quando comparadas com os resultados deste estudo, tais pesquisas novamente enfatizam a importância de uma boa definição de conteúdo das políticas de investimento, bem como das práticas adotadas e sistemas utilizados, lembrando que apenas $1 \%$ das entidades pesquisadas afirmou utilizar um sistema de baseado no VaR para acompanhamento do risco de mercado existente em sua carteira de investimentos.

Ainda tem-se o estudo de Rabelo (2002) que faz um comparativo da regulamentação dos fundos de previdência privada dos países da Organização para Cooperação e Desenvolvimento Econômico (OCDE) e da América Latina, e que aponta a preocupação que esses fundos possuem com relação ao estabelecimento de limites quantitativos para aplicação dos investimentos em diversas instituições e carteiras, promoção de avaliações e auditorias financeiras, entre outras políticas que minimizem os riscos dos fundos de pensão, a fim de garantir retornos e os benefícios futuros. A análise cruzada de resultados novamente demonstra um distanciamento relevante entre as práticas constatadas pela presente pesquisa e as melhores práticas encontradas em entidades comparáveis.

Portanto, é salutar que o MPAS promova as devidas instruções aos gestores dos RPPS para a elaboração de políticas de investimentos e que, ao mesmo tempo, proceda a uma fiscalização efetiva para que essas políticas realmente sejam implementadas.

Consideradas as limitações da presente pesquisa, apresentam-se recomendações para futuras pesquisas com o intuito de demonstrar a importância que a gestão de riscos possui no contexto das organizações. Neste sentido, recomenda-se: a) verificar se houve melhorias com relação às práticas de gestão de riscos adotadas a partir da publicação da Resolução do CMN $\mathrm{n}^{\circ} 3.506 / 2007$; b) ampliar as fontes de dados análises contemplando outros riscos a que esses fundos estão expostos; c) investigar a percepção da gestão de riscos pelos servidores participantes dos RPPS; d) aplicar a pesquisa em outros estados brasileiros.

\section{REFERÊNCIAS}

AFONSO, L. E.; FERNANDES, R. Uma estimativa dos aspectos distributivos da previdência social no Brasil. Revista Brasileira de Economia, vol. 59, n. 3, p. 295-334, 2005.

BODIE, Z. Pension fund investiment policy. Working Paper N. 2752.Cambridge: NBER, 1988.

BOULIER, J.; DUPRÉ, D. Gestão financeira dos fundos de pensão. São Paulo: Pearson Education, 2003. 
BRITO, O.S. Contribuição ao estudo de modelo de controladoria de risco-retorno em bancos de atacado. Tese (Doutorado em Ciências Contábeis) - Departamento de Contabilidade e Atuária (USP), São Paulo, 2000.

BRASIL. Constituição (1988). Emenda Constitucional no 20, de 15 de dezembro de 1998. Disponível em www.planalto.gov.br/ccivil_03/constituicao/emendas/emc/emc20.htm. Acesso em 23 nov 2009.

- Lei no 11.941 de 27 de maio de 2009. Dispõe sobre Regras Gerais a contribuição do Plano de Seguridade do Servidor Público - PSS. Disponível em: www. planalto.gov.br

CONSELHO MONETÁRIO NACIONAL. Resolução CMN/BACEN n⿳0 2.652, de 23 de setembro de 1999. Disponível em: www.bcb.gov.br. Acesso em 15 nov 2007.

CONSELHO MONETÁRIO NACIONAL. Resolução CMN/BACEN no 3244, de 28 de outubro de 2004. Disponível em: www.bcb.gov.br. Acesso em 15 nov 2007.

. CONSELHO MONETÁRIO NACIONAL. Resolução CMN/BACEN no 3506, de 26 de outubro de 2007. Disponível em: www.bcb.gov.br. Acesso em 15 nov 2007.

CONSELHO MONETÁRIO NACIONAL. Resolução CMN/BACEN no 3790, de 24 de setembro de 2009. Disponível em: www.bcb.gov.br. Acesso em 18 jun 2010.

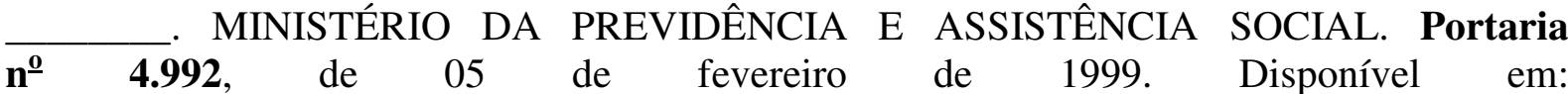
http://www3.dataprev.gov.br/sislex/paginas/66/MPAS/1999/4992.htm. Acesso em 23 nov 2009.

\section{MINISTÉRIO DA PREVIDÊNCIA E ASSISTÊNCIA SOCIAL. Dados}

Estatísticos. Disponível em www.mpas.gov.br. Acesso em 17 set 2007.

SECRETARIA DO TESOURO NACIONAL. Portaria $\mathbf{n}^{\mathbf{0}} \mathbf{6 0 2}$, de 05 de setembro de 2005. Aprova o Código de Ética e Conduta dos Servidores da Secretaria do Tesouro Nacional. Disponível em: www.tesuro.fazenda.gov.br. Acesso em 16 fev 2008.

FABOZZI, F. J. Mercados, análise e estratégias de bônus: (Títulos de Renda Fixa). 3 ed. Rio de Janeiro: Qualitymark, 2000.

FERNANDES, F. C. Uma contribuição à estruturação da atividade de controladoria em entidades fechadas de previdência privada: Uma Abordagem da Gestão Econômica. Tese (Doutorado em Ciências Contábeis) Departamento de Contabilidade e Atuária (USP), São Paulo, 2000.

FERREIRA, B. P. Análise do risco de não superação da meta atuarial em fundos de previdência. Dissertação (Mestrado em Administração) - Centro de Pós-Graduação e Pesquisas em Administração - Universidade Federal de Minas Gerais, Belo Horizonte, 2006.

GARCIA, M. T. M. An analysis of pension funds in Portugal. Pensions: An International Journal. v.9, p.227-245, 2003. 
GULIAS JÚNIOR, S. Risco de mercado e prudência na gestão dos recursos nos fundos de pensão: o Caso da FUNCEF. Dissertação (Mestrado em Ciências Contábeis) - Programa Multiinstitucional e Inter-Regional de Pós-Graduação em Ciências Contábeis - UnB, Brasília, 2005.

HAIR Jr., J. F. et al. Fundamentos de métodos de pesquisa em administração. Porto Alegre: Bookman, 2005.

HELBRONNER, C. L. Pension plan governance and risk management: a Canadian perspective. Pensions: An International Journal. v.10, n.3, p. 221-235. Toronto, 2005.

HERRANZ, B. P. A regulamentação das aplicações dos fundos de pensão no contexto de perigo moral. Dissertação (Mestrado em Administração) Programa de Pós-Graduação em Administração da Fundação Getúlio Vargas (FGV), Rio de Janeiro, 1995.

HOLTON G. A. Defining risk. Financial Analysts Journal. V. 60, n.6, nov/dec, 2004.

JORION, P. Value at Risk: a nova fonte de referências para gestão de risco financeiro. 2. ed..São Paulo: Bolsa de Mercadorias \& Futuros (BM\&F), 2003.

MAROCO, J. Análise estatística com utilização do SPSS. - 2. ed. Lisboa: Sílabo, 2003.

MARSHALL, C. M. Medindo e gerenciando riscos operacionais em instituições financeiras. Rio de Janeiro: Qualitymark, 2002.

RABELO, F. M. Comparative Regulation of private pension plans. Disponível em: http://www.oecd.org/dataoecd.pdf . Acesso em 04 set 2010.

SECURATO, J. R. Decisões financeiras em condições de risco. São Paulo: Atlas, 1993.

TAFNER, P.; GIAMBIAGI, F. (Org). Previdência no Brasil: debates, dilemas e escolhas. Rio de Janeiro: Ipea, 2007.

YERMO, J. Governance and investment of public pension reserve funds in selected OECD countries. OECD WORKING PAPER N. 15, France, 2008.

\section{RESUMO}

O objetivo deste estudo é identificar os mecanismos de controle de riscos adotados pelos gestores dos RPPS nas atividades de investimento. A metodologia da pesquisa é descritiva, do tipo levantamento ou survey, com abordagem quantitativa e com uso da análise de clusters. A pesquisa foi realizada no período de dezembro de 2007 a fevereiro de 2008 nos 303 municípios do estado do Rio Grande do Sul que possuem RPPS constituído, sendo que 84 municípios participaram da pesquisa respondendo ao questionário. Os resultados mostram que $58 \%$ dos gestores dos RPPS pesquisados declararam não possuir uma política de investimentos formalizada; $70 \%$ declararam não adotar as práticas de gestão de investimentos investigadas e 74\% informaram não possuir sistemas de apoio à gestão de investimentos formalizados. O uso da análise de clusters possibilitou a caracterização dos municípios segundo suas práticas de gestão de riscos combinadas com outros indicadores sócioeconômicos. Foram identificados 3 agrupamentos distintos, cuja análise demonstra que as melhores práticas de gestão de riscos nas atividades de investimentos são adotadas pelos RPPS dos municípios mais populosos, onde também foram verificados os maiores volumes de

REAd - Edição 68, Volume 17, No 1, jan/abr 2011 - p. 117-148 
investimento. Conclui-se que, apesar da legislação vigente apresentar avanços com relação à formalização e à adoção de práticas que devem ser consideradas na ocasião da elaboração de uma política de investimentos eficaz, os resultados demonstram que não são adotados mecanismos de controle de riscos para as atividades de investimentos desses fundos.

Palavras-chave: Gestão de riscos, investimento, fundos de aposentadoria, fundos de pensão, Regimes Próprios de Previdência Social.

\section{RISK MANAGEMENT IN INVESTMENT ACTIVITIES OF MUNICIPAL RETIREMENT SYSTEMS OF THE STATE OF RIO GRANDE DO SUL, BRAZIL}

ABSTRACT
The objective of this work is to identify the mechanisms of risk management currently adopted in investment activities of municipal retirement plans (RPPS) of the State of Rio Grande do Sul, Brazil. The methodology applied in the research is descriptive (using survey techniques) and quantitative (using probabilistic research). The research was accomplished in the period of December 2007 to February 2008 in the 303 municipal districts of the State of Rio Grande do Sul that maintain constituted RPPS. The survey received 84 municipal districts responses, allowing the research to reach a 9\% error level in the probabilistic approach. The results of the research demonstrate $58 \%$ of the managers of RPPS declare not to possess a formalized investment policy; $70 \%$ declared not to maintain specific investment management sound practices and $74 \%$ informed they not to have investment management specific support systems. The cluster analysis provided the characterization of districts grouped by risk management practices combined with other socio-economic indicators. Three distinct clusters were identified, showing, as expected, the best practices among the RPPS are adopted by larger districts with larger investment volumes. Finally, in spite of Brazilian regulation recent advances, the results of the research demonstrate that mechanisms of risk control are not adopted in risk management of the investment activities of municipal retirement plans.

Keywords: Risk management, investment, retirement funds, pension funds, municipal retirement plans.

\section{APÊNDICE 1 - INSTRUMENTO DE PESQUISA}

Instruções: O questionário está dividido em 4 partes (A, B, C e D). Por gentileza, responda baseando-se nas práticas existentes no seu Regime Próprio de Previdência (RPPS).

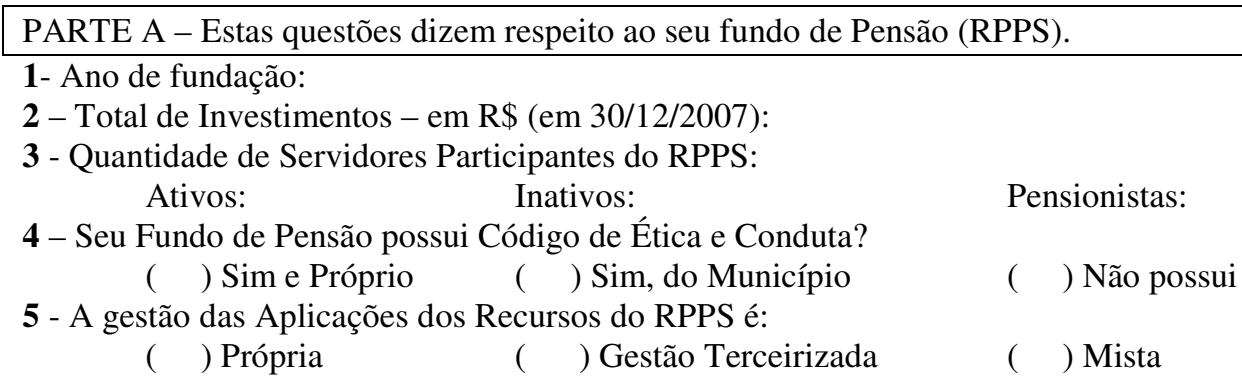

PARTE B - Questões relacionadas à Política de Investimentos

Para cada afirmativa expresse seu grau de concordância, com a seguinte escala:

1 - discordo totalmente; 2 - discordo parcialmente; 3 - não concordo, nem discordo;

4 - concordo parcialmente; 5 - concordo totalmente.

\begin{tabular}{ll|l|l|l|l|l|l|}
\hline Afirmativas & 1 & 2 & 3 & 4 & 5
\end{tabular}

1 Meu RPPS possui política de investimentos formalizada.

2 A política de investimentos de meu RPPS satisfaz os requisitos da Resolução do Conselho Monetário Nacional n 3506/2007.

REAd - Edição 68, Volume 17, No 1, jan/abr 2011 - p. 117-148 
3 A política de investimentos está acessível a todos os servidores participantes do RPPS, ou seja, todos os servidores conhecem a política de investimentos.

4 A política de investimentos estabelece limites de concentração de investimentos em determinados intermediários.

5 A política declara os parâmetros a serem adotados para:

a) cálculo dos níveis de exposição a risco de mercado;

b) estilo da gestão; e

c) avaliação de gestores e administradores de recursos.

6 A política faz menção sobre limites de risco aprovados.

7 A política estabelece padrões e procedimentos para acompanhamento dos ratings das instituições (isto é, das notas recebidas pelas instituições financeiras em avaliações independentes).

8 A política indica a necessidade de segregação de função entre os responsáveis pelas operações de investimentos e os responsáveis pelos processamentos dos documentos.

9 A política menciona as responsabilidades sobre a escolha de alternativas de investimentos:

a) de diretores e funcionários do RPPS;

b) de órgãos de governança (comitês de investimentos e assemelhados);

c) de administradores de recursos contratados.

10 A política exige a definição prévia de limites de crédito a serem observados na condução de negócios com cada intermediário financeiro.

11 Estão claramente identificadas as consequências das violações da política de investimentos.

12 Na formulação e atualização da política participam pessoas com conhecimentos técnicos especializados em gestão de investimentos.

13 Os limites de investimento estabelecidos nas normas do RPPS permitem uma diversificação adequada nos investimentos da entidade.
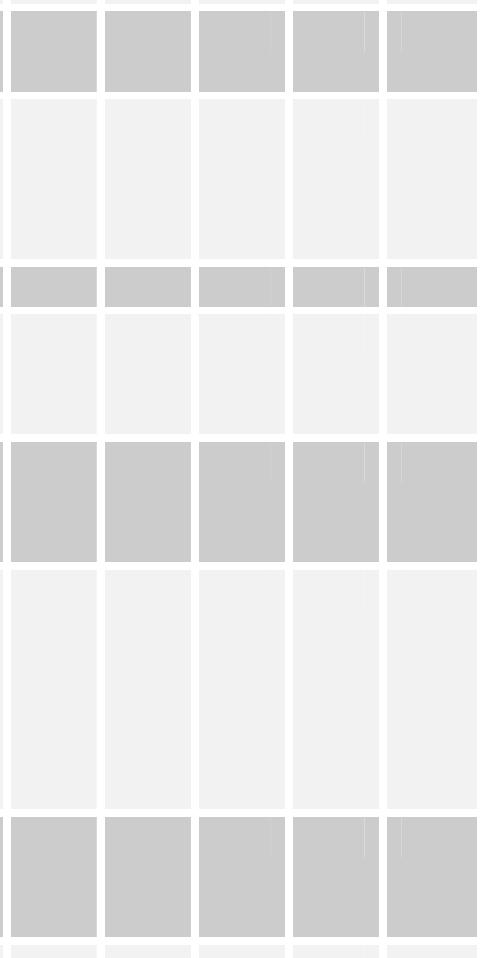


\section{GESTÃO DE RISCO NAS ATIVIDADES DE INVESTIMENTO DOS REGIMES148 \\ PRÓPRIOS DE PREVIDÊNCIA SOCIAL (RPPS) DOS MUNICÍPIOS DO ESTADO \\ DO RIO GRANDE DO SUL}

6 Há regras escritas para orientar o relacionamento com os gestores, custodiantes, corretores, etc.

7 Somente responda se seu Fundo possui gestão própria de recursos .O pessoal que realiza as operações financeiras está bem segregado das atividades de confirmação, reconciliação, reavaliação ou liquidação dessas transações ou do controle do desembolso de caixa ou entrega de outros valores ou pagamentos, tais como margens, comissões, etc. --

PARTE D - Questões relacionadas com os Sistemas de Apoio à Gestão de Investimentos

Para cada afirmativa expresse seu grau de concordância, com a seguinte escala:

1 - discordo totalmente; 2 - discordo parcialmente; 3 - não concordo, nem discordo;

4 - concordo parcialmente; 5 - concordo totalmente.

\begin{tabular}{|l|l|l|l|l|l|} 
Afirmativas & $\mathbf{1}$ & $\mathbf{2}$ & $\mathbf{3}$ & $\mathbf{4}$ & $\mathbf{5}$
\end{tabular}

1 Meu RPPS utiliza modelos quantitativos formais para definir limites dos riscos:

a) de mercado;

b) de crédito; e

c) de liquidez

2 Existem mecanismos de controle de adequação dos níveis de investimentos aos limites determinados com base nos modelos quantitativos.

3 No mandato com os gestores estão considerados e explicados os limites de concentração de ativos calculados com base em modelos quantitativos.

4 Existe informação gerencial suficientemente compreensiva para a gestão de riscos de investimentos.

5 Caso sua entidade possua empresa credenciada para a gestão de recursos do RPPS, essa empresa fornece informações sobre a rentabilidade e o risco das aplicações.

6 Quais os métodos utilizados pelos Gestores de seu fundo para a avaliação de Riscos.

( ) VaR ( ) DNP

( ) Questionários de Controle Interno ～～Marcação de Riscos nos Processos

( ) Outros (especificar)....................................... ( ） Não Há avaliação de Riscos. 